\title{
Device-measured sedentary behavior and physical activity in older adults differ by demographic and health-related factors
}

\author{
Ing-Mari Dohrn ${ }^{1,2^{*}}$ (D), Paul A. Gardiner ${ }^{3}$, Elisabeth Winkler ${ }^{4}$ and Anna-Karin Welmer ${ }^{1,2,5,6}$
}

\begin{abstract}
Background: Our aim was to describe and explore older adults' device-measured sedentary behavior and physical activity (PA) pattern by sex, age, education, marital status, body mass index, and physical function; and to assess agreement regarding fulfillment of PA recommendations, i.e. $150 \mathrm{~min} /$ week of moderate-to-vigorous intensity PA (MVPA), between device-measured and self-reported PA.

Method: We included 656 older adults (64\% women), aged $66,81-87$ or $\geq 90$ years from a Swedish populationbased cohort study. The activPAL3 accelerometer provided information on sedentary behavior (sedentary time, sedentary bouts, sit-to-stand transitions) and PA. Stepping $\geq 100$ steps/min was considered MVPA; standing and stepping < 100 steps/min were considered light-intensity PA (LPA). Self-reported PA was compared with min/week in MVPA and steps/day.
\end{abstract}

Results: On average, $60 \%$ of wear time was spent sedentary, 36\% in LPA, and $4 \%$ in MVPA. Relative to men, women, had significantly $(p<0.05)$ more sit-to-stand transitions, spent $33 \mathrm{~min} /$ day less sedentary and $27 \mathrm{~min} /$ day more in LPA, and were more likely to report meeting PA recommendations, but showed no difference in steps/day, MVPA, or sedentary bout duration. Older age was associated with more sedentary time, lower MVPA and fewer steps/day. The prevalence of meeting PA recommendations was 59\% device-measured and $88 \%$ by self-report with limited agreement between methods (Cohen's Kappa $=0.21$, Spearman's rho $=0.28$ ). Age differences were much more pronounced with objective measures than by self-report.

Conclusions: We found significant sex differences in sedentary behavior and time in LPA in older adults, but not in MVPA, in contrast to previous findings. Sedentary time increased with age, with small differences in accumulation pattern. MVPA time was lower with older age, obesity, and poor physical function. A majority of the participants > 80 years did not meet the PA recommendations. Given the strong relationships between sedentary behavior, PA and health in older adults, programs are needed to address these behaviors. Agreement between device-measured and self-reported fulfillment of PA recommendations was limited. Device-based measurement adds value to PA studies, providing richer and different data than self-report.

Keywords: Accelerometery, Cohort study, Sitting, Validation

\footnotetext{
* Correspondence: ing-mari.dohrn@ki.se

'Division of Physiotherapy, Department of Neurobiology, Care Sciences and

Society, Karolinska Institutet, SE-141 83 Huddinge, Sweden

${ }^{2}$ Aging Research Center, Department of Neurobiology, Care Sciences and

Society (NVS), Karolinska Institutet and Stockholm University, Stockholm,

Sweden

Full list of author information is available at the end of the article
}

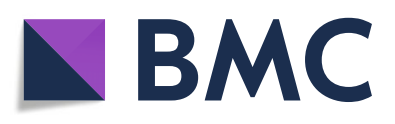

() The Author(s). 2020 Open Access This article is licensed under a Creative Commons Attribution 4.0 International License, which permits use, sharing, adaptation, distribution and reproduction in any medium or format, as long as you give appropriate credit to the original author(s) and the source, provide a link to the Creative Commons licence, and indicate if changes were made. The images or other third party material in this article are included in the article's Creative Commons licence, unless indicated otherwise in a credit line to the material. If material is not included in the article's Creative Commons licence and your intended use is not permitted by statutory regulation or exceeds the permitted use, you will need to obtain permission directly from the copyright holder. To view a copy of this licence, visit http://creativecommons.org/licenses/by/4.0/. The Creative Commons Public Domain Dedication waiver (http://creativecommons.org/publicdomain/zero/1.0/) applies to the data made available in this article, unless otherwise stated in a credit line to the data. 


\section{Introduction}

Physical activity (PA) is essential for healthy aging. Older adults who are physically active have lower rates of allcause mortality and many chronic diseases, a lower risk of falling, better physical function and better cognitive function [1]. The robust evidence on the health benefits of PA has led to public health PA guidelines recommending that adults $\geq 65$ years should accumulate at least $150 \mathrm{~min} /$ week of moderate-to-vigorous intensity PA (MVPA), i.e. $\geq 3$ metabolic equivalents (METs) [1], with brisk walking often used as a primary example of an appropriate activity. In addition, muscle strengthening activities should be performed two or more days per week. Yet, adherence to PA recommendations is low in older adults, with studies relying on self-reported data indicating that 55 to $70 \%$ do not achieve the minimum level of MVPA [2, 3].

Additionally, older people may spend up to $80 \%$ of their waking day sedentary [4-9] and the sedentary time seems to increase with age. Growing scientific evidence has recognized that sedentary behavior is a distinct risk factor for poor health, including increased risk of mortality, type 2 diabetes, metabolic syndrome, cardiovascular disease and cancer [10-12]. Sedentary behavior is measured in varied ways but consistently defined as any waking behavior characterized by an energy expenditure $\leq 1.5 \mathrm{METs}$, while in a sitting, reclining or lying posture [13]. Research suggests that not only the total time spent sedentary is of importance, but also the pattern of how the sedentary time is accumulated, i.e., prolonged vs shorter sedentary bouts or how frequently sedentary time is interrupted. Interruptions to sedentary time (breaks) play an important role for cardio-metabolic health $[14,15]$, and may also be associated with muscle mass and physical function in older adults [16-18].

It is known that self-reported data have low accuracy due to recall bias or social desirability. Sedentary time is often underestimated and MVPA is often overestimated, while light-intensity PA (LPA), which is common among older adults, is almost impossible to recall or report accurately [19-21]. It is therefore highly relevant to use devicebased methods, which more accurately can capture the whole PA intensity spectrum, as well as other aspects of the daily movement pattern, for example sedentary time in bouts. Body-worn activity monitors, such as accelerometers, are shown to be sensitive and feasible for measuring PA and sedentary behavior in older adults, although it has been sparsely used in the oldest age groups. Studies that have used accelerometry to assess PA and sedentary behavior in individuals over 70 years have found that patterns differ according to gender, age group, education, and body mass index (BMI) [4, 6-9, 22].

To date, most evidence on associations between devicebased sedentary behavior and health has derived from accelerometers defining sedentary behavior as lack of movement, in contrast to measures derived from actual sitting posture. This can lead to misclassification of lowintensity non-sedentary behavior, such as standing [23]. The thigh-mounted activPAL3 is an accelerometer that directly measures the postural aspect of sedentary behavior, i.e. sitting/lying vs upright position, and thereby also more accurately can capture breaks in sedentary time by registering sit-to-stand transitions [23]. Richer knowledge of older adults' pattern of sedentary time accumulation and PA in both light and moderate-to-vigorous intensity can guide development of health promoting efforts tailored for older people. Therefore, our aims were to describe and explore older adults' device-measured sedentary behavior and PA pattern by sex, age, education, marital status, BMI and physical function; and to compare agreement regarding fulfillment of PA recommendations between device-measured and self-reported PA.

\section{Method \\ Study population and data collection}

We used data from the ongoing population-based Swedish National study on Aging and Care in Kungsholmen (SNAC-K) study. The study sample consists of persons randomly selected from eleven age groups $\geq 60$ years living at home or in nursing homes in Kungsholmen, Stockholm. Details of the original sampling methods and response rates are presented elsewhere [24]. Briefly, $\mathrm{n}=$ 3363 (73\% of eligible people) in the ages $60,66,72,78,81$, $84,87,90,93,96$, and 99 participated in the baseline examination 2001-2004. Follow-up examinations are performed every six years for younger cohorts (60-78 years) and every three years for older cohorts ( $\geq 78$ years). At the follow-up examinations 2016-2018, $\mathrm{n}=1287$ participants in the age groups $66,81,84,87,90$ and $\geq 93$ years were examined. Out of those, $n=680$ participants who were eligible (no severe cognitive impairment; able to move indoors without assistance) agreed to wear an accelerometer the following week and comprise the study population in this study. Data were collected through interviews and tests at the SNAC-K research center or in the participants' homes by trained staff.

\section{Socio-demographic and health variables}

Age, sex, education (less than high school, high school, or university) and marital status (i.e. married/living together (yes/no), and use of walking aid (yes/no) were derived from interviews. BMI was calculated from weight and height measured using standard methods and categorized as underweight $<20$, normal 20-24, overweight $25-29$, and obese $\geq 30 \mathrm{~kg} / \mathrm{m}^{2}$, adapted for older adults [25]. For the analyses of age-related differences in sedentary behavior and PA we categorized participants into three age groups: 66 years, $81-87$ years, and $\geq 90$ years. 


\section{Physical function}

Physical function was assessed with the 5 times sit to stand test (5 STS). The 5 STS was performed by asking the participants to stand up and sit down five times as fast as they could, without using the arms, and categorized as ability to perform five consecutive chair stands (yes/no) [26]. In addition, the balance test one-leg stance (OLS), eyes open, was used to describe the sample. Each leg was tested twice, and the best overall score was used and categorized as ability to stand $\geq 5 \mathrm{~s}$ (yes/no) [27].

\section{Self-reported PA}

Self-reported PA derived from two questions in a selfadministered questionnaire distributed by the study nurse to be completed by the participants after the examination [28]: 1) "Do you regularly engage in light exercise? (Walking on roads or in parks, walking in the woods, short bicycle rides, light aerobics, golf)" and 2) "Do you regularly engage in more intense exercise? (Jogging, brisk long walks, heavy-duty gardening, long bicycle rides, highintensity aerobics, long distance ice skating, skiing, swimming, ball sports (not golf) or other similar activity)". For both questions the answer alternatives were; "In the last 12 months: every day, several times/week, 2-3 times/ month, less, never." The answers from the two PA questions were collapsed into a dichotomous variable (yes/no) with reference to the recommended PA for health [1]. Participants were considered meeting recommendations if they were engaged in light and/or intense exercise every day or several times per week, and not meeting recommendations if they chose the other response options.

\section{Assessment of sedentary behavior and PA}

The activPAL3 accelerometer (PAL Technologies Ltd., Glasgow, UK) was used to assess sedentary behavior and PA. The activPAL3 is a small and slim thigh-worn activity monitor that uses triaxial acceleration to determine thigh angle and thus body posture (sitting/lying or upright), along with transitions between these postures, and stepping speed (cadence), from which energy expenditure can be estimated. The activPAL3 has high accuracy for measuring time spent sedentary (i.e., sitting/lying), standing or stepping, and for pattern of sedentary time accumulation [23]. Participants were asked to continue with their usual PA habits while wearing the activPAL3 for seven consecutive days during all waking hours (excluding showering and swimming), starting the day after the examination, and to record time when they put on and removed the device each day on a log-sheet. The study nurse provided verbal, visual, and written instructions to participants during the examination at the research center or home visit on how to wear the device correctly. The participants were provided with a Micropore $2.5 \mathrm{~cm}$ tape for sensitive skin to adhere the activPAL3 to the thigh and with a prepaid envelope to return the device by mail.

\section{Data processing activPAL3}

The activPAL3 files were processed using the PALbatch software, using a feature to correct for upside down wear. A custom-made syntax for SAS programming system was used for further analyses of the events files from the PALbatch software and to remove log-reported nonwear time [29]. Consistent with recommendations for the field [23], visual examination of heat maps was performed to check consistency between recorded movement and the times provided in the log-sheet, making corrections when appropriate (e.g., participant had confused $\mathrm{AM}$ and $\mathrm{PM}$ ) and estimating missing non-wear or sleep times. Accelerometer data of participants' with least four valid measurement days, were included in the data analysis. A measurement day was considered valid if wear time was at least $10 \mathrm{~h}$ during waking hours.

Prior work has shown that $100 \mathrm{steps} / \mathrm{min}$ is an appropriate threshold value for 3 METs [30], consequently, we used cadence of $\geq 100$ steps/min for MVPA, and total time spent either stepping at a cadence $<100$ steps/min or standing for LPA. Variables from the activPAL3 were: number of steps/ day, daily time in MVPA and daily time in LPA (defined as described above), daily sedentary time, number of sit-stand transitions per sedentary hour (a similar concept to breaks in sedentary time), usual bout duration (midpoint of the cumulative distribution of sedentary bout durations, i.e. half of all sedentary time is accumulated in bouts longer than the usual bout duration) [31], and longest sedentary bout.

For tests of agreement with self-reported PA, three dichotomous variables (yes/no) were created from the activPAL3 data to classify if a person was considered to meet the aerobic PA recommendations. The first variable derived from the median daily time spent in MVPA multiplied by seven and participants with at least $150 \mathrm{~min} /$ week of stepping with a cadence $\geq 100$ steps/min were considered to have met PA recommendation. Neither prolonged nor regular activity during the week were required. The other two variables derived from the daily step count with cutoffs set at 7000 and 5000 steps/day. A level of approximately 7000 steps/day has been suggested to equal $\geq 150 \mathrm{~min} /$ week MVPA in older adults [32, 33]. However, 7000 steps/day may be a too high goal for some older adults, especially in the oldest age groups. Therefore, we also compared with 5000 steps/day, which may be a more realistic level and a level shown to relate to better health outcomes [34].

\section{Statistical analyses}

Descriptive data are presented as numbers and proportions (\%), mean and standard deviation (SD), or median 
and interquartile range. Due to skewed MVPA data, we used multivariate quantile regression for continuous variables to assess differences in daily movement pattern within subgroups reported as adjusted average median and $95 \%$ confidence intervals (CI) of individual means. For dichotomous data we used multivariate logistic regression presented as adjusted proportions of individual means or odds ratios and CI. Covariates included in the models were sex, age group, education, marital status, BMI, physical function, and accelerometer wear time.

The relationships between self-reported and accelerometer derived data were calculated with Cohen's kappa to determine the kappa coefficient (K), with confidence intervals $(\mathrm{CI})$ and Spearman's correlations (rho). The kappa coefficient adjusts for the agreement attributable to chance and is recommended when validating PA questions with categorical measures [35]. Statistical significance was defined as two-tailed $p<$ 0.05 . Analyses were computed in Stata 15.1 (StataCorp LP, College Station, TX, USA) and SAS 9.4 (SAS Institute Inc., NC, USA).

\section{Results}

\section{Participant characteristics}

Out of the 680 persons who wore an accelerometer, 24 persons were excluded due to either device malfunction $(\mathrm{n}=4)$, device not worn according to the instructions $(\mathrm{n}=$ $2)$ or $<4$ valid days $(n=18)$, leaving an analytical sample of $n=656$. Compared to the participants that were excluded or declined to wear the device, the analytical sample included a larger proportion of the 66 years age group (58\% vs $26 \%$ ) and a smaller proportion of the $81-87$ and $\geq$ 90 years age groups ( $37 \%$ vs 50 and $4.5 \%$ vs $24 \%$ ). There we no differences in the proportion of women between the excluded and analytical sample (both 64\%). The majority of the participants $(78 \%)$ had seven accelerometer wear days and mean wear time per day was $14 \mathrm{~h}$ and 12 $\mathrm{min}$. Due to missing self-reported data, the sample size for analyses of agreement between device-measured and selfreported PA was $n=619$.

\section{Sedentary behavior and PA by subgroups}

Table 1 shows participant characteristics and crude daily movement pattern presented as percentages of wear

Table 1 Characteristics of the total study population and by sex and age group

\begin{tabular}{|c|c|c|c|c|c|c|}
\hline & Total $(n=656)$ & Women $(n=420)$ & Men $(n=236)$ & 66 y $(n=383)$ & $81-87$ y $(n=243)$ & $\geq 90$ y $(n=30)$ \\
\hline Age & $73.3( \pm 9.0)$ & $74.1( \pm 9.3)$ & $71.7( \pm 8.2)$ & $66.0( \pm 1.0)$ & $82.6( \pm 2.3)$ & $91.1( \pm 2.3)$ \\
\hline \multicolumn{7}{|l|}{ Sex } \\
\hline Women & $420(64)$ & $\mathrm{n} / \mathrm{a}$ & $\mathrm{n} / \mathrm{a}$ & $228(59)$ & $165(68)$ & $17(90)$ \\
\hline \multicolumn{7}{|l|}{ Education } \\
\hline University & $375(57)$ & $223(53)$ & $152(64)$ & $255(66)$ & $111(46)$ & $9(30)$ \\
\hline \multicolumn{7}{|l|}{ Marital status } \\
\hline Married/living together & $367(56)$ & $193(46)$ & $174(74)$ & $252(66)$ & $113(46)$ & $2(7)$ \\
\hline \multicolumn{7}{|l|}{ Body mass index } \\
\hline Underweight, $<20$ & $25(4)$ & $24(6)$ & $1(0.5)$ & $9(2)$ & $14(6)$ & $2(7)$ \\
\hline Normal, 20-24 & $287(44)$ & $200(48)$ & $87(37)$ & $171(45)$ & $102(42)$ & $14(47)$ \\
\hline Overweight, 25-29 & 254 (39) & $140(33)$ & $114(48)$ & $151(39)$ & $92(38)$ & $11(37)$ \\
\hline Obese, $\geq 30$ & $89(13)$ & $55(13)$ & $34(14)$ & $52(14)$ & $34(14)$ & $3(10)$ \\
\hline \multicolumn{7}{|l|}{ Physical function } \\
\hline One-leg-stance $\geq 5 \mathrm{~s}$ & $587(90)$ & $292(72)$ & $180(79)$ & $354(92)$ & $110(49)$ & $8(28)$ \\
\hline 5 STS test, able to & $472(74)$ & $372(89)$ & $215(92)$ & $375(98)$ & $197(82)$ & $15(52)$ \\
\hline Use walking aid & $82(10)$ & $69(17)$ & $13(5.5)$ & $7(2)$ & $57(24)$ & $18(60)$ \\
\hline \multicolumn{7}{|l|}{ Physical activity } \\
\hline Sedentary, $\%$ of wear time & $60.2( \pm 10.8)$ & $59.1( \pm 10.4)$ & $62.1( \pm 10.8)$ & $58.3( \pm 10.9)$ & $62.2( \pm 9.9)$ & $67.3( \pm 11.1)$ \\
\hline Light PA, $\%$ of wear time & $36.1( \pm 10.1)$ & $37.3( \pm 9.9)$ & $34.1( \pm 10.1)$ & $37.0( \pm 10.4)$ & $35.4( \pm 9.2)$ & $31.1( \pm 10.6)$ \\
\hline MVPA, $\%$ of wear time & $3.6( \pm 3.0)$ & $3.6( \pm 2.9)$ & $3.7( \pm 3.1)$ & $4.6( \pm 3.0)$ & $2.4( \pm 2.3)$ & $1.6( \pm 2.8)$ \\
\hline Steps/day & $8696( \pm 3779)$ & $8571( \pm 3820)$ & $8918( \pm 3704)$ & $10,106( \pm 3573)$ & $6952( \pm 3011)$ & $4818( \pm 3390)$ \\
\hline Accelerometer wear time, min/day & $852( \pm 64)$ & $850( \pm 62)$ & $857( \pm 66)$ & $866( \pm 62)$ & $834( \pm 60)$ & $831( \pm 66)$ \\
\hline Self-reported regular ${ }^{a}$ MVPA $^{b}$ & $542(88)$ & $353(88)$ & $189(86)$ & $326(90)$ & $194(85)$ & $22(76)$ \\
\hline
\end{tabular}

Data are reported as numbers (\%) or mean $( \pm \mathrm{SD})$. ${ }^{\mathrm{a}}$ Every day or several times/week, ${ }^{\mathrm{b}} \mathrm{n}=619 . \mathrm{MVPA}=$ moderate-to-vigorous physical activity; PA $=$ physical activity; 5 STS $=5$ times sit to stand test 
time spent sedentary, in LPA, and in MVPA, and mean steps/day for all study participants and stratified by sex and age group. Median daily time sedentary was $8 \mathrm{~h} 32$ min, $5 \mathrm{~h} 2 \mathrm{~min}$ in LPA, and $26 \mathrm{~min}$ in MVPA for the total sample. Steps/day ranged from 987 to 23,475 (minmax), with a median of 8371. A majority of the day was spent sedentary in both women and men, and across age groups, with group means ranging from 58 to $67 \%$ of wear time. Proportion of time in LPA ranged from $31 \%$ in the $\geq 90$ group to $37.5 \%$ among those with normal BMI, with small but significant differences in all subgroups except education. Proportion of time in MVPA ranged from $1.6-4.6 \%$, with least activity registered in the $\geq 90$ group and the highest in 66 year olds. Women spent median 33 min less sedentary and 27 min more in LPA than men, while MVPA or steps/day did not vary statistically significant by sex.

In Table 2, sedentary behavior among all study participants and stratified by subgroups is presented. Women had more sit-to-stand transitions per hour of sedentary time than men, but there were no significant sex differences regarding sedentary bout duration. Older age was associated with more sedentary time, fewer sit-to-stand transition and longer usual sedentary bout. The length of usual sedentary bout ranged from 8 to $84 \mathrm{~min}$, and only $5 \%$ of the sample had a usual sedentary bout over $80 \mathrm{~min}$. Individuals who were unable to do 5 STS spent $40 \mathrm{~min} /$ day more sedentary and had fewer sit-to-stand transitions compared with those who were able to do 5 STS, on average.

Time spent in MVPA and fulfillment of MVPA recommendations are shown in Table 3 for all study participants and by subgroups. The prevalence of meeting PA recommendations ranged from 59\% $(\geq 150 \mathrm{~min} /$ week stepping at $\geq 100$ steps/min cadence) to $88 \%$ (self-reports being active in MVPA every day or several days/week). Median MVPA time was significantly lower to a large degree with older age, obesity, and poor physical function, and significantly lower to a smaller degree with less education. These patterns were largely reflected in the patterning of prevalence of meeting physical activity recommendations, though not all differences were statistically significant. Age differences were much more pronounced with the objective measures than by selfreport. Additionally, relative to men, women were significantly more likely to meet $\geq 150 \mathrm{~min} /$ week MVPA

Table 2 Sedentary behavior among all study participants and in subgroups

\begin{tabular}{|c|c|c|c|c|}
\hline & Sedentary time (min/day) & Sit-to-stand transitions ( $\mathrm{n}$ ) & Usual sedentary bout (min) & Longest sedentary bout (min) \\
\hline Total sample ${ }^{a}$ & $512.1(455.6-571.7)$ & $5.1(4.0-6.4)$ & $30.1(24.4-39.1)$ & $132.6(106.4-167.2)$ \\
\hline \multicolumn{5}{|l|}{ Sex } \\
\hline Women & $502.6(492.2-513.1)^{*}$ & $5.3(5.1-5.5)^{*}$ & $30.5(28.8-32.1)$ & $135.0(128.1-141.9)$ \\
\hline Men & $535.6(521.6-549.9)$ & $4.8(4.5-5.1)$ & $31.3(30.1-32.4)$ & $133.1(128.0-138.2)$ \\
\hline \multicolumn{5}{|l|}{ Age group } \\
\hline 66 years & $504.5(493.3-515.8)^{*}$ & $5.4(5.2-5.6)^{*}$ & $29.9(28.6-31.2)^{*}$ & $133.2(127.7-138.7)$ \\
\hline $81-87$ years & $526.0(511.9-540.1)$ & $4.8(4.5-5.0)$ & $32.0(30.3-33.6)$ & $134.3(127.4-141.2)$ \\
\hline$\geq 90$ years & $552.3(510.6-593.9)$ & $4.5(3.7-5.3)$ & $37.4(32.6-42.3)$ & $137.4(117.0-157.8)$ \\
\hline \multicolumn{5}{|l|}{ Education } \\
\hline$\leq$ High school & $516.5(503.8-529.3)$ & $5.0(4.8-5.3)$ & $31.4(30.0-32.9)$ & 133.7 (127.4-139.9) \\
\hline University & $513.0(502.1-524.0)$ & $5.2(5.0-5.4)$ & $30.7(29.4-32.0)$ & $133.9(128.5-139.2)$ \\
\hline \multicolumn{5}{|l|}{ Marital status } \\
\hline Living alone & $526.2(513.3-539.0)^{*}$ & $5.0(4.8-5.3)$ & $31.4(29.8-32.9)$ & $134.7(128.4-141.0)$ \\
\hline Married/partner & $505.4(494.1-516.7)$ & $5.2(4.9-5.4)$ & $30.7(29.4-32.0)$ & $133.1(127.6-138.6)$ \\
\hline \multicolumn{5}{|l|}{ Body mass index } \\
\hline Underweight < 20 & $512.0(469.7-554.4)$ & $5.6(4.8-6.4)^{*}$ & $26.9(22.0-31.9)^{*}$ & $130.3(109.6-151.0)$ \\
\hline Normal 20-24 & $501.5(489.0-513.9)$ & $5.4(5.2-5.7)$ & $29.0(27.6-30.5)$ & $130.0(124.0-136.1)$ \\
\hline Overweight 25-29 & $520.6(507.4-534.0)$ & $5.0(4.7-5.2)$ & $32.0(30.5-33.6)$ & 134.8 (128.3-141.3) \\
\hline Obese $\geq 30$ & $539.6(517.4-561.8)$ & $4.4(4.0-4.8)$ & $35.5(32.9-38.1)$ & 143.7 (132.9-154.6) \\
\hline \multicolumn{5}{|l|}{ Physical function } \\
\hline 5 STS, not able to & $550.1(521.9-578.2)^{*}$ & $4.3(3.8-4.9)$ & $35.3(32.0-38.6)^{*}$ & $144.4(130.6-158.1)$ \\
\hline 5 STS, able to & $510.6(502.0-519.3)$ & $5.2(5.0-5.4)$ & $30.5(29.5-31.5)$ & 132.6 (128.4-136.9) \\
\hline
\end{tabular}

Data are reported as average median (confidence intervals), adjusted for all other listed variables plus wear time, ${ }^{*} \mathrm{p}<0.05$ within subgroups. ${ }^{a}$ Unadjusted median and interquartile range. 5 STS $=5$ times sit to stand test 
Table 3 Time in MVPA and fulfillment of different defined MVPA recommendations

\begin{tabular}{|c|c|c|c|c|c|}
\hline & MVPA min/d & $\geq 150 \mathrm{~min} / \mathrm{w}$ MVPA & $\geq 7000 \mathrm{steps} / \mathrm{d}$ & $\geq 5000 \mathrm{steps} / \mathrm{d}$ & Self-reported regular $\mathrm{PA}^{\mathrm{b}}$ \\
\hline Total sample & $25.8(10.9-44.8)$ & 59 & 64 & 84 & 88 \\
\hline \multicolumn{6}{|l|}{ Sex } \\
\hline Women & $27.3(24.9-29.8)$ & $64^{*}$ & 67 & 91 & 91 \\
\hline Men & $23.9(20.6-27.2)$ & 54 & 66 & 89 & 86 \\
\hline \multicolumn{6}{|l|}{ Age group } \\
\hline 66 years & $32.4(29.7-35.1)^{*}$ & $75^{*}$ & $78^{*}$ & $95^{*}$ & 90 \\
\hline $81-87$ years & $17.6(14.3-20.9)$ & 38 & 51 & 79 & 88 \\
\hline$\geq 90$ years & $12.5(2.7-22.3)$ & 23 & 22 & 61 & 86 \\
\hline \multicolumn{6}{|l|}{ Education } \\
\hline$\leq$ High school & $23.7(20.7-26.7)^{*}$ & $55^{*}$ & $56^{*}$ & 88 & $86^{*}$ \\
\hline University & $27.8(25.3-30.4)$ & 64 & 74 & 91 & 91 \\
\hline \multicolumn{6}{|l|}{ Marital status } \\
\hline Living alone & $25.4(22.3-28.4)$ & 62 & 63 & $87^{*}$ & 86 \\
\hline Married/partner & $26.6(24.0-29.3)$ & 59 & 70 & 92 & 91 \\
\hline \multicolumn{6}{|l|}{ Body mass index } \\
\hline Underweight < 20 & $36.7(26.8-46.7)^{*}$ & $85^{*}$ & $70^{*}$ & $95^{*}$ & 89 \\
\hline Normal 20-24 & $29.4(26.5-32.3)$ & 69 & 76 & 93 & 91 \\
\hline Overweight 25-29 & $24.8(21.7-27.9)$ & 58 & 65 & 88 & 89 \\
\hline Obese $\geq 30$ & $16.1(10.9-21.4)$ & 29 & 38 & 80 & 77 \\
\hline \multicolumn{6}{|l|}{ Physical function } \\
\hline 5 STS, not able to & $15.7(9.1-22.3)^{*}$ & $33^{*}$ & 49 & $78^{*}$ & $79^{*}$ \\
\hline 5 STS, able to & $27.2(25.2-29.3)$ & 63 & 67 & 91 & 90 \\
\hline
\end{tabular}

Data are reported as average median (confidence interval) or proportions in \%, adjusted for all other listed variables plus wear time, * $\mathrm{p}<0.05$ within subgroups.

annadjusted median (interquartile range). ${ }^{\mathrm{b}} \mathrm{n}=619$. MVPA $=$ moderate-to-vigorous physical activity; $5 \mathrm{STS}=5$ times sit to stand test

recommendation ( $64 \%$ vs $54 \%)$ with smaller and nonsignificant differences by sex seen for the other measures. Differences by marital status were small $(<10 \mathrm{~min}$, $<10 \%$ ), and were significant only for meeting $\geq 5000$ steps/day.

\section{Agreement regarding fulfillment of PA recommendations}

Table 4 shows the concurrent validity for self-reported PA vs accelerometer derived PA for identifying participants classified as sufficiently active according to PA recommendations, expressed as Spearman's rho (relative validity) and Cohen's kappa coefficient (agreement). In the total sample, agreement between self-report and device-measured $\geq 150 \mathrm{~min} /$ week MVPA was fair ( $\mathrm{K}=$ 0.21 ) [36], and the correlation was weak (rho $=0.28$ ) but significant. Similar results were seen with the other criteria. The overall validity was not reflective of the results seen in each subgroup, with especially low validity seen in the oldest age group and those unable to perform the 5 STS test (particular in terms of kappa, which is chance-corrected), and with especially good validity seen in underweight participants (BMI <20). Both relative validity and agreement were higher in men than in women. The kappa agreement for $\geq 150 \mathrm{~min} /$ week MVPA was highest in the 66 years age group and in participants living alone $(K=0.25)$. Agreement between self-report and steps/day was higher than for $\geq 150 \mathrm{~min} /$ week MVPA overall.

\section{Discussion}

In this study aiming to describe and explore older adults' device-measured pattern of sedentary time and PA by subgroups, we found that women spent about $30 \mathrm{~min}$ less sedentary and equivalent more time activities of light intensity, such as household chores or slow walking. These sex differences are in line with similar populations in Europe $[4,8,9]$ and may be of importance for health. Previous research has shown that substituting 30 min of sedentary time to LPA may reduce the risk of allcause mortality with $11 \%$ and risk of cardiovascular disease with $24 \%$ [37]. Interestingly, there were only small sex differences in pattern of sedentary time accumulation. Total sedentary time was higher with increasing age. Pattern of sedentary time accumulation varied by age group, but the differences in number of sit-to-stand transitions and usual sedentary bout duration were quite 
Table 4 Concurrent validity for self-reported physical activity and accelerometer derived physical activity

\begin{tabular}{|c|c|c|c|c|c|c|}
\hline \multirow[t]{2}{*}{ Characteristics (n) } & \multicolumn{2}{|c|}{$\geq 150$ min/week MVPA stepping ${ }^{a}$} & \multicolumn{2}{|l|}{$\geq 7000$ steps/day } & \multicolumn{2}{|l|}{$\geq 5000$ steps/day } \\
\hline & Spearman's rho & Kappa (95\% Cl) & Spearman's rho & Kappa (95\% Cl) & Spearman's rho & Kappa $(95 \%$ Cl) \\
\hline All (619) & 0.28 & $0.21(0.15-0.28)$ & 0.31 & $0.25(0.18-0.32)$ & 0.32 & $0.32(0.22-0.42)$ \\
\hline Women (400) & 0.27 & $0.20(0.13-0.28)$ & 0.30 & $0.23(0.15-0.31)$ & 0.31 & $0.30(0.18-0.42)$ \\
\hline Men (219) & 0.29 & $0.22(0.12-0.32)$ & 0.34 & $0.30(0.17-0.42)$ & 0.36 & $0.36(0.19-0.54)$ \\
\hline \multicolumn{7}{|l|}{ Age group } \\
\hline 66 years (361) & 0.29 & $0.25(0.14-0.36)$ & 0.35 & $0.32(0.20-0.44)$ & 0.31 & $0.29(0.12-0.46)$ \\
\hline $81-87$ years (229) & 0.24 & $0.14(0.07-0.21)$ & 0.25 & $0.17(0.08-0.25)$ & 0.32 & $0.30(0.16-0.44)$ \\
\hline$\geq 90$ years $(29)$ & $0.26^{\#}$ & $0.12(-0.01-0.25)$ & $0.22^{\#}$ & $0.10(-0.01-0.21)$ & $0.27^{\#}$ & $0.20(-0.04-0.45)$ \\
\hline \multicolumn{7}{|l|}{ Education } \\
\hline$\leq$ High school (268) & 0.28 & $0.22(0.13-0.30)$ & 0.25 & $0.19(0.10-0.27)$ & 0.38 & $0.37(0.23-0.51)$ \\
\hline University (351) & 0.25 & $0.19(0.10-0.27)$ & 0.35 & $0.29(0.18-0.40)$ & 0.23 & $0.23(0.08-0.38)$ \\
\hline \multicolumn{7}{|l|}{ Marital status } \\
\hline Living alone (275) & 0.32 & $0.25(0.15-0.34)$ & 0.30 & $0.23(0.14-0.32)$ & 0.31 & $0.30(0.17-0.44)$ \\
\hline Married/partner (344) & 0.23 & $0.17(0.08-0.25)$ & 0.31 & $0.25(0.15-0.35)$ & 0.31 & $0.32(0.16-0.47)$ \\
\hline \multicolumn{7}{|l|}{ Body mass index } \\
\hline Underweight < 20 (22) & $0.42^{\#}$ & $0.40(-0.07-0.87)$ & 0.53 & $0.43(0.07-0.79)$ & $0.23^{\#}$ & $0.23(-0.31-0.76)$ \\
\hline Normal 20-24 (278) & 0.25 & $0.19(0.09-0.30)$ & 0.24 & $0.20(0.08-0.31)$ & 0.39 & $0.38(0.21-0.56)$ \\
\hline Overweight 25-29 (233) & 0.23 & $0.16(0.07-0.26)$ & 0.30 & $0.23(0.12-0.34)$ & 0.29 & $0.28(0.12-0.44)$ \\
\hline Obese $\geq 30$ (85) & 0.32 & $0.21(0.09-0.33)$ & 0.33 & $0.25(0.10-0.39)$ & 0.24 & $0.24(0.01-0.47)$ \\
\hline \multicolumn{7}{|l|}{ Physical function } \\
\hline 5 STS, not able to (59) & $0.23^{\#}$ & $0.14(0.01-0.26)$ & $0.20^{\#}$ & $0.13(-0.02-0.28)$ & 0.39 & $0.35(0.14-0.57)$ \\
\hline 5 STS, able to (555) & 0.27 & $0.20(0.13-0.27)$ & 0.31 & $0.25(0.17-0.32)$ & 0.28 & $0.28(0.16-0.39)$ \\
\hline
\end{tabular}

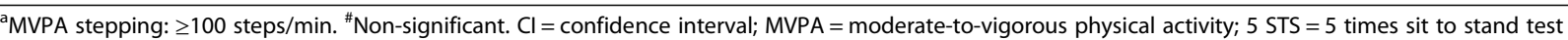

small, with no differences in longest sedentary bout. Sedentary behavior did not vary by education or marital status except for total sedentary time, which was $20 \mathrm{~min} /$ day more in those who were living alone. Obese participants spent $40 \mathrm{~min} /$ day more sedentary than those with normal weight on average and they also had a less favorable sedentary accumulation pattern. These differences were also seen for individuals with impaired physical function.

We did not find statistically significant sex differences in time spent in MVPA or number of daily steps. This is in contrast to many other studies, both those using self-reports and accelerometers, which found males to be significantly more active than females [38]. It is known that many PA questionnaires give examples of MVPA activities that traditionally are mostly performed by men, especially in older generations, and therefore are likely to underestimate MVPA in older women. However, recent device-based studies have also found that MVPA is higher in men $[4,8,39,40]$. In our study, on the contrary, we found that women were more likely to fulfil the PA recommendations of $150 \mathrm{~min} /$ week of MVPA than men in the adjusted models. Similar findings have previously been reported in two Norwegian studies [9, 41], and the discrepancies might depend on cultural and sociodemographic differences between older adults in the Nordic countries and other study populations.

As reported in previous research [4, 8], overweight and obese participants spent significantly less time in MVPA and had lower fulfillment of MVPA recommendations, compared to normal weight participants. Surprisingly, our underweight participants had a high level of MVPA. Underweight in older adults is often related to frailty and a lower muscle mass, which would be expected to result in lower MVPA. However, it is likely that our finding is a consequence of selection bias, and that our small sample of underweight participants, 24 woman and 1 man, consists of well-functioning, active older adults. Education level is another known correlate of PA [42], and this is consistent with what we found for MVPA, but not for sedentary behavior or LPA.

In our study sample, $26 \%$ of the participants were not able to do five chair raises without help from their arms. These older adults were significantly less active than those who could perform the test, with over $9 \mathrm{~h}$ /day sedentary and only $15 \mathrm{~min} /$ day in MVPA, which is clearly under the recommended PA level. 
Importantly, we also found that they had a lower number of sit-to-stand transitions and longer usual sedentary bout, suggesting that difficulty in raising from a chair may lead to a more sedentary behavior. Even though studies have found that breaks in sedentary time are associated with better health outcomes $[16,18]$, evidence is still inconclusive and more research, including prospective studies, is needed to gain a deeper understanding of these associations. Considering the negative health effects of prolonged sedentary behavior and a low PA level, it should be highlighted that this is a group of older adults that may benefit from interventions aiming to decrease sedentary time and increase MVPA. For example, a replacement of just $10 \mathrm{~min}$ of sedentary time with MVPA could result in a $34 \%$ reduction of cardiovascular mortality risk [37].

In agreement with other studies [8, 43], we found a wide variation in time in MVPA and steps/day within all age groups, indicating that high levels of PA may be sustained even among the oldest old. Two participants in the $\geq 90$ group had a daily average of $>10,000$ steps. However, when considering the data from study participants in this oldest age group, it is important to acknowledge that the results reflect those who have successfully aged and are able and willing to participate, and thereby represent a selective sample. Still, there is limited data on PA and sedentary behavior in the oldest old, and as the number of nonagenarians and centenarians are increasing worldwide, our results may contribute with valuable information about this group.

Walking is the most popular and most commonly reported form of physical activity in older adults, and to provide generalized guidance of the desired daily activity to meet the recommendations of $150 \mathrm{~min} /$ week of MVPA, a level of approximately 7000 steps/day has been suggested by the American college of Sports Medicine [33]. However, recognizing that the normative range for number of steps/day for older adults is 2000-9000 [32] and that many older adults may be limited in their everyday activities due to mobility limitations and chronic illness, we chose also to compare with 5000 steps/day as the threshold.

The age-related prevalence of meeting the PA recommendations of $150 \mathrm{~min} /$ week of MVPA ranged from $75 \%$ in the 66 years group to $23 \%$ in the $\geq 90$ group, with very similar results if the 7000 steps/day definition was used. The few previous studies that have assessed devicemeasured PA in older adults divided by age groups have also shown that PA decreased progressively with age for both men and women $[9,38]$. If the 5000 steps/day level was used, $95 \%$ in the 66 years group met the goal and $61 \%$ in the $\geq 90$ group. This suggests that many of the oldest old, may find the recommendations challenging, and highlights the importance of a broad perspective when counselling older sedentary individuals [44]. A focus on the message to reduce sedentary time and increase light activities may be more realistic and pave the way to physical activity with higher intensity. The doseresponse relation between physical activity and health clearly shows that there are benefits from any level of $\mathrm{PA}$, and more is better [10].

The kappa agreement between self-reported and device-based MVPA was fair overall [36], which is in line with other studies. Previous validations of one or two PA questions using accelerometry assessed MVPA have found correlations of rho $=0.31$ [45] and rho $=0.38$ [46], and $K=0.18$ [46]. Even more comprehensive PA questionnaires, and thereby possibly more accurate, have limited correlations in older populations ranging from rho $=0.11-0.65[19]$.

Validation studies of self-report measures of sedentary time (usually 'sitting') have shown it is difficult for older people to accurately recall their behavior $[19,20]$. Wearing devices can give people an accurate estimate of their behavior and therefore shape how they choose to respond to messages to sit less (as in the physical activity guidelines of many countries) and to ascertain the effectiveness of any changes to reduce their sedentary behavior. The same is true for PA. If we can develop better methods of self-report or cheaper devices that accurately measure these behaviors, then individuals can choose how to respond to that information. Our results add to the current knowledge that older adults sit for long periods and have low levels of PA, which are both suitable targets for change.

This study has several strengths. One important strength is the use of the activPAL3 accelerometer, which is a posture-based activity monitor. By using this device, we could investigate pattern of sedentary time accumulation in a more reliable way than studies using hip or wrist worn accelerometers, which estimate sedentary time based on limited acceleration rather than posture. The activPAL3 has also shown good accuracy in measuring steps in older adults who walk slowly and use an assistive device [47]. It might be worth noticing that the sedentary time derived from the activPAL3 can include reclining or lying during waking hours; however, these positions are included in the definition of sedentary time [13]. Another important strength is the population-based study sample, including 133 participants over 84 years. Further, a sample size of at least 50 participants has been suggested for validation studies on PA questionnaires [48]. The sample size in our study was over 650 participants, which made it possible to draw stronger conclusions, and to perform stratified analyses for subgroups. We used Cohen's kappa for 
reporting results on the validity of the PA questions which is a considered a better choice of method for categorical measures than the often-used Spearman's rho $[19,35]$.

A limitation of our study is that the design did not allow us to include participants with cognitive impairment or mobility limitations, leading to a study sample healthier than the general older population. It is also a limitation that the cadence of $\geq 100$ steps $/ \mathrm{min}$ used to define MVPA has not been validated for older adults, and some misclassification may have occurred. Ideally PA intensity cut points should be individually calibrated; nevertheless, this is not feasible in large study samples, a limitation shared with similar research. As in many other accelerometer studies, activities such as cycling, strength training, water-based activities, upper body movements and the effort of carrying loads were not captured. Additionally, even though we made a large effort to estimate wear time correctly, it must be acknowledged that the longest sedentary bout variable is sensitive to miscalculation of wear time. The overall wear time was high but is still likely to have missed some of all activities, since a 24-h wear protocol was not used, and participants did not always attach the devices immediately upon rising or immediately before bed. Further, our self-reported data provided information regarding the intensity and frequency of PA, but not the duration of the activity. Still, it is hard to accurately recall how many minutes that are spent in different activities in a day or week, especially unstructured activity interspersed over the day. Regular activities at a moderate intensity with longer durations are easier to recall and it is reasonable to assume that people reporting being active every day or several times per week also achieve the recommended PA level. The device-measured PA was collected over the entire year for different individuals and would thereby not be affected by season on a group level. Still, it is a limitation to the study that device-based PA was assessed over one week, while self-reported PA was asked about for the past 12 months. It should also be noted that, even though it is included in the PA recommendations [1], we did not investigate muscle strengthening physical activity. Finally, due to the cross-sectional design of this study we cannot draw any causal conclusions from the results.

\section{Conclusions}

We found significant sex differences in daily sedentary behavior and LPA in older adults, but not in MVPA, in contrast to previous findings in self-reports. Women spent on average about $30 \mathrm{~min} /$ day less sedentary and equivalent more time performing activities of light intensity than men. Sedentary time increased with older age, with small differences in pattern of sedentary time accumulation. Individuals with limitations in physical function spent over $9 \mathrm{~h} /$ day sedentary and only $15 \mathrm{~min} /$ day in MVPA. A majority of the participants over 80 years did not meet the PA recommendations of 150 min/week of MVPA. Age differences were much more pronounced with objective measures than by self-report. The limited agreement between device-measured and self-reported fulfillment of PA recommendations illustrate the consequences of using different methodological approaches in PA surveillance. Device-based measurement adds value to studies, providing richer and different data than self-report, such as more detailed amounts and sedentary behavior. Given the strong relationships between sedentary behavior, PA and health in older adults, programs are needed to address these behaviors. A better understanding of sex and age differences in sedentary behavior and PA in older adults can inform interventions and guide public health messages.

\section{Acknowledgements}

We thank the SNAC-K participants and the SNAC-K Group for their collaboration in data collection and management.

\section{Ethical approval \\ The Regional Ethics Review Board in Stockholm has approved the study (dnr: KI 01-114, 2016/730-31/1. Written informed consent has been collected from all participants}

\section{Authors' contributions}

IMD and AKW designed the study. IMD performed the analyses, interpreted the results and drafted the manuscript. EW assisted with analyses. AKW, PG and EW contributed to interpretations of results and editing of the manuscript. All authors read and approved the final manuscript.

\section{Funding}

SNAC-K is supported by the Swedish Ministry of Health and Social Affairs and the participating county councils and municipalities. This study was supported by The Loo and Hans Osterman's foundation for geriatric research, and Strategic Research Area Health Care Science (SFO-V), Karolinska Institutet, to [IMD]. Open access funding provided by Karolinska Institute.

\section{Availability of data and materials}

The datasets used during the current study are available from maria. wahlberg@ki.se, on reasonable request.

\section{Consent for publication}

Not applicable.

\section{Competing interests}

The authors declare that they have no competing interests.

\section{Author details}

${ }^{1}$ Division of Physiotherapy, Department of Neurobiology, Care Sciences and Society, Karolinska Institutet, SE-141 83 Huddinge, Sweden. ${ }^{2}$ Aging Research Center, Department of Neurobiology, Care Sciences and Society (NVS), Karolinska Institutet and Stockholm University, Stockholm, Sweden. ${ }^{3}$ Centre for Health Services Research, The University of Queensland, Brisbane, Australia. ${ }^{4}$ School of Public Health, The University of Queensland, Brisbane, Australia. ${ }^{5}$ Allied Health Professionals, Function Area Occupational Therapy \& Physiotherapy, Karolinska University Hospital, Stockholm, Sweden.

${ }^{6}$ Stockholm Gerontology Research Center, Stockholm, Sweden. 
Received: 25 February 2020 Accepted: 1 June 2020

Published online: 11 June 2020

\section{References}

1. WHO. Global recommendations on physical activity for health. Physical Activity and Older Adults. https://www.who.int/dietphysicalactivity/ factsheet_olderadults/en/ Downloaded: 2020-01-13.

2. Keadle SK, McKinnon R, Graubard BI, Troiano RP. Prevalence and trends in physical activity among older adults in the United States: a comparison across three national surveys. Prev Med. 2016;89:37-43. https://doi.org/10. 1016/j.ypmed.2016.05.009.

3. Rydwik E, Welmer AK, Kareholt I, Angleman S, Fratiglioni L, Wang HX. Adherence to physical exercise recommendations in people over 65--the SNAC-Kungsholmen study. Eur J Pub Health. 2013;23(5):799-804. https://doi. org/10.1093/eurpub/cks150.

4. Arnardottir NY, Koster A, Van Domelen DR, Brychta RJ, Caserotti P, Eiriksdottir $G$, et al. Objective measurements of daily physical activity patterns and sedentary behaviour in older adults: age. Gene/Environment Susceptibility-Reykjavik Study Age and ageing. 2013:42(2):222-9. https://doi. org/10.1093/ageing/afs160.

5. Harvey JA, Chastin SF, Skelton DA. How Sedentary are older people? A systematic review of the amount of Sedentary behavior. J Aging Phys Act. 2015;23(3):471-87. https://doi.org/10.1123/japa.2014-0164.

6. Jefferis BJ, Parsons TJ, Sartini C, Ash S, Lennon LT, Papacosta O, et al. Objectively measured physical activity, sedentary behaviour and all-cause mortality in older men: does volume of activity matter more than pattern of accumulation? Br J Sports Med. 2019;53(16):1013-20. https://doi.org/10. 1136/bjsports-2017-098733.

7. Koolhaas CM, van Rooij FJA, Schoufour JD, Cepeda M, Tiemeier H, Brage S, et al. Objective measures of activity in the elderly: distribution and associations with demographic and health factors. J Am Med Dir Assoc. 2017;18(10):838-47. https://doi.org/10.1016/j.jamda.2017.04.017.

8. van Ballegooijen AJ, van der Ploeg HP, Visser M. Daily sedentary time and physical activity as assessed by accelerometry and their correlates in older adults. Eur Rev Aging Phys Act. 2019;16:3. https://doi.org/10.1186/s11556019-0210-9.

9. Lohne-Seiler H, Hansen BH, Kolle E, Anderssen SA. Accelerometerdetermined physical activity and self-reported health in a population of older adults (65-85 years): a cross-sectional study. BMC Public Health. 2014; 14:284. https://doi.org/10.1186/1471-2458-14-284.

10. Ekelund U, Tarp J, Steene-Johannessen J, Hansen BH, Jefferis B, Fagerland MW, et al. Dose-response associations between accelerometry measured physical activity and sedentary time and all cause mortality: systematic review and harmonised meta-analysis. Bmj. 2019;366:14570. https://doi.org/ 10.1136/bmj.l4570

11. de Rezende LF, Rey-Lopez JP. Matsudo VK, do Carmo Luiz O. Sedentary behavior and health outcomes among older adults: a systematic review BMC public health. 2014;14:333. https://doi.org/10.1186/1471-2458-14-333.

12. Wilmot EG, Edwardson CL, Achana FA, Davies MJ, Gorely T, Gray LJ, et al. Sedentary time in adults and the association with diabetes, cardiovascula disease and death: systematic review and meta-analysis. Diabetologia. 2012; 55(11):2895-905. https://doi.org/10.1007/s00125-012-2677-z.

13. Sedentary Behaviour Research N. Letter to the editor: standardized use of the terms "sedentary" and "sedentary behaviours". Appl Physiol Nutr Metab. 2012;37(3):540-2. https://doi.org/10.1139/h2012-024.

14. Dunstan DW, Kingwell BA, Larsen R, Healy GN, Cerin E, Hamilton MT, et al. Breaking up prolonged sitting reduces postprandial glucose and insulin responses. Diabetes Care. 2012;35(5):976-83. https://doi.org/10.2337/dc11-1931.

15. Healy GN, Dunstan DW, Salmon J, Cerin E, Shaw JE, Zimmet PZ, et al. Breaks in sedentary time: beneficial associations with metabolic risk. Diabetes Care. 2008;31(4):661-6. https://doi.org/10.2337/dc07-2046.

16. Reid N, Healy GN, Gianoudis J, Formica M, Gardiner PA, Eakin EE, et al. Association of sitting time and breaks in sitting with muscle mass, strength, function, and inflammation in community-dwelling older adults. Osteoporosis Int. 2018;29(6):1341-50. https://doi.org/10.1007/s00198-018-4428-6.

17. Sardinha LB, Santos DA, Silva AM, Baptista F, Owen N. Breaking-up sedentary time is associated with physical function in older adults. J Gerontol A Biol Sci Med Sci. 2015;70(1):119-24. https://doi.org/10.1093/ gerona/glu193.

18. Rosenberg DE, Bellettiere J, Gardiner PA, Villarreal VN, Crist K, Kerr J. Independent associations between Sedentary behaviors and mental, cognitive, physical, and functional health among older adults in retirement communities. J Gerontol A Biol Sci Med Sci. 2016;71(1):78-83. https://doi. org/10.1093/gerona/glv103.

19. Helmerhorst HJ, Brage S, Warren J, Besson H, Ekelund U. A systematic review of reliability and objective criterion-related validity of physical activity questionnaires. Int J Behav Nutr Phys Act. 2012;9:103. https://doi.org/10. 1186/1479-5868-9-103.

20. Prince SA, Saunders TJ, Gresty K, Reid RD. A comparison of the effectiveness of physical activity and sedentary behaviour interventions in reducing sedentary time in adults: a systematic review and meta-analysis of controlled trials. Obes Rev. 2014;15(11):905-19. https://doi.org/10.1111/obr.12215.

21. Warren JM, Ekelund U, Besson H, Mezzani A, Geladas N, Vanhees L, et al. Assessment of physical activity - a review of methodologies with reference to epidemiological research: a report of the exercise physiology section of the European Association of Cardiovascular Prevention and Rehabilitation. Eur J Cardiov Prev R. 2010;17(2):127-39. https://doi.org/10.1097/HJR. Ob013e32832ed875

22. Bellettiere J, Carlson JA, Rosenberg D, Singhania A, Natarajan L, Berardi V, et al. Gender and age differences in hourly and daily patterns of Sedentary time in older adults living in retirement communities. PLoS One. 2015;10(8): e0136161. https://doi.org/10.1371/journal.pone.0136161.

23. Edwardson CL, Winkler EAH, Bodicoat DH, Yates T, Davies MJ, Dunstan DW, et al. Considerations when using the activPAL monitor in field-based research with adult populations. J Sport Health Sci. 2017;6(2):162-78. https:// doi.org/10.1016/j.jshs.2016.02.002.

24. Lagergren M, Fratiglioni L, Hallberg IR, Berglund J, Elmstahl S, Hagberg B, et al. A longitudinal study integrating population, care and social services data. The Swedish national study on aging and care (SNAC). Aging Clin Exp Res. 2004;16(2):158-68. https://doi.org/10.1007/BF03324546.

25. Launer $L$, Harris T. Weight, height and body mass index distributions in geographically and ethnically diverse samples of older persons. Ad hoc committee on the statistics of anthropometry and aging. Age Ageing. 1996; 25(4):300-6. https://doi.org/10.1093/ageing/25.4.300.

26. Seeman TE, Charpentier PA, Berkman LF, Tinetti ME, Guralnik JM, Albert M, et al. Predicting changes in physical performance in a high-functioning elderly cohort: MacArthur studies of successful aging. J Gerontol. 1994;49(3): M97-108. https://doi.org/10.1093/geronj/49.3.m97.

27. Vellas BJ, Wayne SJ, Romero L, Baumgartner RN, Rubenstein LZ, Garry PJ. One-leg balance is an important predictor of injurious falls in older persons. J Am Geriatr Soc. 1997;45(6):735-8. https://doi.org/10.1111/j.1532-5415.1997.tb01479.x.

28. Lindwall M, Rennemark M, Halling A, Berglund J, Hassmen P. Depression and exercise in elderly men and women: findings from the Swedish national study on aging and care. J Aging Phys Act. 2007;15(1):41-55. https://doi.org/10.1123/japa.15.1.41.

29. Winkler EA, Bodicoat DH, Healy GN, Bakrania K, Yates T, Owen N, et al. Identifying adults' valid waking wear time by automated estimation in activPAL data collected with a 24 h wear protocol. Physiol Meas. 2016; 37(10):1653-68. https://doi.org/10.1088/0967-3334/37/10/1653.

30. Tudor-Locke C, Han H, Aguiar EJ, Barreira TV, Schuna JM Jr, Kang M, et al. How fast is fast enough? Walking cadence (steps/min) as a practical estimate of intensity in adults: a narrative review. Br J Sports Med. 2018; 52(12):776-88. https://doi.org/10.1136/bjsports-2017-097628.

31. Chastin SFM, Winkler EAH, Eakin EG, Gardiner PA, Dunstan DW, Owen N, et al. Sensitivity to change of objectively-derived measures of Sedentary behavior. Meas Phys Educ Exerc Sci. 2015;19(3):138-47. https://doi.org/10. 1080/1091367X.2015.1050592.

32. Tudor-Locke C, Craig CL, Aoyagi Y, Bell RC, Croteau KA, De Bourdeaudhuij I, et al. How many steps/day are enough? For older adults and special populations. Int J Behav Nutr Phy. 2011;8. https://doi.org/10.1186/14795868-8-80.

33. Garber CE, Blissmer B, Deschenes MR, Franklin BA, Lamonte MJ, Lee IM, et al. American College of Sports Medicine position stand. Quantity and quality of exercise for developing and maintaining cardiorespiratory, musculoskeletal, and neuromotor fitness in apparently healthy adults: guidance for prescribing exercise. Med Sci Sports Exerc. 2011;43(7):1334-59. https://doi.org/10.1249/MSS.0b013e318213fefb.

34. Tudor-Locke C, Craig CL, Thyfault JP, Spence JC. A step-defined sedentary lifestyle index: < 5000 steps/day. Appl Physiol Nutr Metab. 2013;38(2):100-14. https://doi.org/10.1139/apnm-2012-0235.

35. Terwee CB, Bot SD, de Boer MR, van der Windt DA, Knol DL, Dekker J, et al. Quality criteria were proposed for measurement properties of health status 
questionnaires. J Clin Epidemiol. 2007;60(1):34-42. https://doi.org/10.1016/j. jclinepi.2006.03.012.

36. Landis JR, Koch GG. The measurement of observer agreement for categorical data. Biometrics. 1977 Mar;33(1):159-74.

37. Dohrn IM, Kwak L, Oja P, Sjostrom M, Hagstromer M. Replacing sedentary time with physical activity: a 15-year follow-up of mortality in a national cohort. Clin Epidemiol. 2018;10:179-86. https:/doi.org/10.2147/CLEP.S151613.

38. Sun F, Norman IJ, While AE. Physical activity in older people: a systematic review. BMC Public Health. 2013;13:449. https://doi.org/10.1186/1471-2458-13-449.

39. Davis MG, Fox KR, Hillsdon M, Sharp DJ, Coulson JC, Thompson JL. Objectively measured physical activity in a diverse sample of older urban UK adults. Med Sci Sports Exerc. 2011;43(4):647-54. https://doi.org/10.1249/ MSS.0b013e3181f36196.

40. Jones SA, Wen F, Herring AH, Evenson KR. Correlates of US adult physical activity and sedentary behavior patterns. J Sci Med Sport. 2016;19(12):1020-7. https://doi.org/10.1016/j.jsams.2016.03.009.

41. Viken H, Aspvik NP, Ingebrigtsen JE, Zisko N, Wisloff U, Stensvold D. Correlates of objectively measured physical activity among Norwegian older adults: the generation 100 study. J Aging Phys Act. 2016;24(2):369-75. https://doi.org/10.1123/japa.2015-0148.

42. Bauman AE, Reis RS, Sallis JF, Wells JC, Loos RJ, Martin BW, et al. Correlates of physical activity: why are some people physically active and others not? Lancet. 2012;380(9838):258-71. https://doi.org/10.1016/501406736(12)60735-1.

43. Davis MG, Fox KR. Physical activity patterns assessed by accelerometry in older people. Eur J Appl Physiol. 2007;100(5):581-9. https://doi.org/10.1007/ s00421-006-0320-8.

44. Sparling PB, Howard BJ, Dunstan DW, Owen N. Recommendations for physical activity in older adults. BMJ. 2015 Jan 21;350:h100. https://doi.org/ 10.1136/bmj.h100.

45. Ekblom Ö, Ekblom-Bak E, Bolam KA, Ekblom B, Schmidt C, Söderberg S, et al. Concurrent and predictive validity of physical activity measurement items commonly used in clinical settings- data from SCAPIS pilot study. BMC public health. 2015;15(1). doi: https://doi.org/10.1186/s12889-015-2316-y.

46. Smith BJ, Marshall AL, Huang N. Screening for physical activity in family practice: evaluation of two brief assessment tools. Am J Prev Med. 2005; 29(4):256-64. https://doi.org/10.1016/j.amepre.2005.07.005.

47. Hergenroeder AL, Barone Gibbs B, Kotlarczyk MP, Kowalsky RJ, Perera S, Brach JS. Accuracy of objective physical activity monitors in measuring steps in older adults. Gerontol Geriatr Med. 2018 Jun 17;4: 2333721418781126. https://doi.org/10.1177/2333721418781126.

48. Forsén L, Loland NW, Vuillemin A, Chinapaw MJ, van Poppel MN, Mokkink LB, et al. Self-administered physical activity questionnaires for the elderly: a systematic review of measurement properties. Sports Med. 2010;40(7):601-23. https:/doi.org/10.2165/11531350-000000000-00000

\section{Publisher's Note}

Springer Nature remains neutral with regard to jurisdictional claims in published maps and institutional affiliations.

Ready to submit your research? Choose BMC and benefit from:

- fast, convenient online submission

- thorough peer review by experienced researchers in your field

- rapid publication on acceptance

- support for research data, including large and complex data types

- gold Open Access which fosters wider collaboration and increased citations

- maximum visibility for your research: over $100 \mathrm{M}$ website views per year

At BMC, research is always in progress.

Learn more biomedcentral.com/submissions 